ISSN 2658-4824 (Print), 2713-3095 (Online)

УДК 78.01

DOI: 10.33779/2658-4824.2021.1.052-060

\section{Т.Ш. ГЕРШБЕЙН}

Университет имени Бар-Илана

г. Рамат-Ган, Израиль

ORCID: 0000-0003-4282-1491

tatiana854@gmail.com

\section{TATIANA SH. GERSHBEYN}

\author{
Bar-Ilan University \\ Ramat Gan, Israel \\ ORCID: 0000-0003-4282-1491 \\ tatiana854@gmail.com
}

\section{Направленное образное представление: к вопросу о терапевтическом влиянии барочной музыки}

На протяжении веков проблема воздействия музыки на человека интересовала философов и мыслителей, порождая многочисленные теории и концепции. Серьёзным этапом в развитии музыкальной терапии явилась эпоха барокко. Впервые учёными была предпринята попытка систематизации средств музыкальной выразительности по принципу их восприятия, а музыкальные произведения, созданные в этот период, широко используются и в современной музыкальной терапии. Барочная инструментальная музыка, положенная в основу метода направленного образного представления, плодотворна для занятий с пожилыми людьми, страдающими болезнью Альцгеймера. Направленное образное представление под музыку традиционно является начальным этапом группового психотерапевтического процесса и используется для подготовки участников к сеансу психодрамы. На основании существующих систем (Хелен Бонни, Джозеф Морено) автором статьи разработана самостоятельная методика, цель которой - установление и расширение вербальной коммуникации с больными на средней (умеренной) стадии болезни Альцгеймера. Помимо основных задач, достижение которых преследуют занятия по направленному образному представлению, музыка, подобранная с учётом индивидуальных

\section{Directed Figurative Imagery: Regarding the Question of the Therapeutic Influence of Baroque Music}

During the course of many centuries the problem of the impact of music on human beings has aroused interest in philosophers and thinkers, generating numerous theories and conceptions. A serious stage of development of musical therapy occurred in the Baroque era. During that period for the first time scholars made the attempt to provide a systematization of the means of musical expressivity according to the principle of their perception, while the musical compositions created during that period are also broadly used in present-day musical therapy. Baroque instrumental music taken as a principle for the method of the directed figurative perception is seminal for working with elderly people with Alzheimer's disease. Figurative perception and directed apprehension of music are traditionally considered to be the initial stage of a group psychotherapeutic process and is used for preparation of the participants for a session of psychodrama. On the basis of existing systems (those of Helen Bonny and Joseph Moreno) the author of the article developed an independent methodology, the aim of which is to establish and expand verbal communication with patients at an intermediate (moderate) stage of the Alzheimer disease. In addition to the main goals the achievement of which is pursued by activities in directed figurative perception, the music chosen in consideration of the patient's individual characteristic features arouses a therapeutic impact on him, being conducive to the rehabilitation 
характеристик пациента, оказывает на него терапевтическое воздействие, способствуя восстановлению личностных воспоминаний и оптимизации психоэмоционального состояния человека.

\section{Ключевые слова:}

музыкальная терапия, Хелен Бонни, Джозеф Морено, музыка барокко, направленное образное представление, музыка и болезнь Альцгеймера. of personal memories and the optimization of the human being's psycho-emotional state.

Keywords:

musical therapy, Helen Bonny, Joseph Moreno, music of the Baroque era, directed figurative perception, music and Alzheimer disease.

\section{Для цитирования/For citation:}

Гершбейн Т.Ш. Направленное образное представление: к вопросу о терапевтическом влиянии барочной музыки // ИКОНИ / ICONI. 2021. № 1. С. 52-60.

DOI: 10.33779/2658-4824.2021.1.052-060.

То, что жизнь отнимает, музыка возвращает.

$\mathrm{C}$ древнейших времён темы, связанные с влиянием музыки на человека, привлекали внимание философов, поэтов, мыслителей, учёных. Известно, что в Древней Греции музыка ценилась выше, чем архитектура и живопись. Так, Сократ, обучавшийся музыке, видел в ней одно из средств достижения душевного здоровья, а Платон указывал на тесную связь между музыкальными стилями и политическими законами. В Древнем Египте хоровым пением исцеляли от бессонницы, в Древнем Китае прописывали определённые мелодии для излечения болезней, а в Древней Индии верили, что музыка создаёт особый настрой, приближающий человека к миру трансцендентального.

Проблема восприятия музыки получила новое освещение в эпоху барокко. Впервые в трудах учёных рассматривалась направленность музыки на активизацию эмоциональных состояний и чувств человека. Именно с XVII века широко утверждается понимание музыки как выразительного языка, способного передать достаточно определённые, по мнению теоретиков той эпохи, чувства и представления. Немецкий учёный Атаназиус Кирхер в трактате Musurgia Universalis (1650) наделяет музыку «музыкальным магнетизмом», способностью вызывать в душе определённые аффекты. Кирхер выделяет восемь главных: радость, отвага, гнев, страсть, прощение, страх, надежда, сострадание; а также несколько "производных", разделяя все аффекты на три группы - радость, спокойствие, печаль [1, с. 60]. Он описывает условия, при которых музыкальное произведение может вызвать наиболее сильные аффекты, выделяя факторы, влияющие на восприятие музыки: место, время дня, время года. Кирхер обращает внимание на размер произведения, его пропорции и время, которые должны быть согласованы с духом воспринимающего [6, с. 309]. Учёный утверждает, что существует связь между музыкальными вкусами и природным темпераментом человека: «Меланхолики любят серьёзную, непрерывающуюся, грустную гармонию, сангвиники благодаря лёгкой возбудимости кровяных паров всегда привлекаются танцевальным стилем. К таким же гармоническим движениям 
стремятся и холерики, у которых танцы приводят к сильному воспалению желчи. Флегматиков трогают тонкие женские голоса» [9, с. 283]. Кирхер, изучая психотерапевтические возможности музыки и пения, пришёл к выводу, что физиологические процессы в теле человека подвержены влиянию музыкальных сфер (ритма, мелодии, пения).

Исследованиям в области музыкальной терапии в определённой мере соответствовали музыкальные произведения эпохи барокко: их целительные свойства отмечали учёные и в последующие эпохи. Определяя барочную музыку как музыку порядка, многие исследователи XX века утверждали, что она «благодаря своей чёткой структуре ритма и звука усиливает впечатление равновесия» [2, с. 122]. Ироничное высказывание врача и музыкального терапевта А. Понтуика «в совершенной музыке есть свои подводные рифы. Она столь совершенна, что выводит из равновесия» [2, с. 123] лишь подчёркивает сложность и неоднозначность предмета исследования.

Болгарский психолог Г. Лозанов предлагал учащимся слушать барочную музыку и одновременно письменно отвечать на вопросы для мобилизации неисчерпаемых творческих ресурсов правого полушария мозга. «Музыка барокко приводит мозг в состояние гармонии. В частности, она даёт эмоциональный ключ к суперпамяти: открывает лимбическую систему мозга. Эта система не только обрабатывает эмоции, но и является соединительным звеном между сознательным и подсознательным отделами мозга» [7, с. 165]. По его мнению, причина усиления способности поглощать и вспоминать информацию заключается в темпе этой музыки (60-70 ударов в минуту), что приближается к частоте сердцебиения. Данная гипотеза была подтверждена при измерениях частоты электромагнитных волн головного мозга («альфа-волны» частотой 7 Гц являются причиной особого эмоционально-творческого состояния человека). На основании исследований, проведённых со студентами во время выполнения письменных заданий, учёные пришли к выводу, что ритмика музыки барокко стимулирует припоминание информации, влияет на развитие интуиции, внимания человека и умения давать обоснованные оценки при выражении внутренних чувств и наклонностей [5, с. 59].

В работе с пожилыми людьми, страдающими болезнью Альцгеймера, какиелибо измерения проблематичны, более важными параметрами в процессе музыкальных занятий становятся улыбка, зрительный контакт и вербальная коммуникация. Плодотворным представляется использование музыкальных произведений эпохи барокко в методиках, сочетающих музыку и образное представление. Корни подобных практик, основанных на способности музыки стимулировать релаксацию и подкреплять образное воображение, - в древних обрядах исцеления, распространённых во многих культурах мира.

Одним из признанных методов второй половины XX века является система музыкального терапевта Хелен Бонни «Направленное образное представление под музыку», суть которого - в слушании музыки в расслабленном состоянии с целью вызвать в воображении определённые образы и символы. На основе этой практики музыкальный терапевт Джозеф Морено основал свой «Метод образного представления под музыку», используя его как разогрев для занятий психодрамой [4, с. 89]. Занятие начинается с релаксации: участники сидят или лежат в удобных позах в слабо освещённой комнате с закрытыми глазами, концентрируются на своём дыхании, постепенно расслабляя мышцы тела. С началом звучания музыки терапевт зачитывает определённый сценарий, последующие этапы процесса носят психотерапевтический характер и требуют от ведущего навыков работы по этой методике. 
Музыкальный терапевт Дорит Амир, анализируя различные техники GIM (Guided Imagery and Music) [10, с. 110], выводит четыре уровня, присущие каждому методу, сочетающему образы и музыку:

1. Эстетический/абстрактный уровень. Восприятие музыки характеризуется визуальными и кинестетическими образами. Цель - получение удовольствия от музыки. Ощущения кажутся обычными, но они более интенсивны.

2. Психодинамический уровень включает вытесненные воспоминания, личностные и межличностные конфликты. Образы или символы прошлого выходят на поверхность сознания, происходит поиск решения проблем.

3. Перинатальный уровень основан на ранних воспоминаниях: роды, смерть, возрождение; происходит осознание телесных травм, физиологических проблем.

4. Трансперсональный уровень - расширение рамок сознания за пределы Эго, ощущение единства, святости, нахождение вне времени и пространства.

Идея сочетания музыки и образного представления, адаптированная для пациентов гериатрических отделений, воплотилась в своеобразные «Музыкальные путешествия» - методику, разработанную автором этой статьи в соответствии с потребностями пожилых людей, страдающих болезнью Альцгеймера на второй стадии заболевания. Клинический социолог Наоми Файл характеризует подобных пациентов, «дезориентированных во времени», согласно её терминологии, следующим образом: «снижение зрения и слуха, постепенное нивелирование запахов, ухудшение двигательных способностей и деградация когнитивных функций подготавливают почву для замкнутости и ухода в себя. Человек всё меньше держится за действительность, он не способен придерживаться хронологии, не может правильно сориентироваться во временных параметрах. Поражение мозга влияет на центры управления: человек не может владеть собой, он теряет ком- муникативные способности» [11, с. 76]. Вывести пациента из замкнутого круга, в который его заточила болезнь, вернуть ему способность к общению и связному повествованию, вызвать значимые для человека воспоминания, улучшить его психоэмоциональное состояние - основные цели методики «Музыкальных путешествий».

В начале занятия желательно порассуждать с пожилым человеком о том, что музыка, как и литература, связана с определённым географическим местом и историческим периодом, соответственно, с музыкальным произведением можно «путешествовать» в пространстве и времени. Далее инструктор объясняет, что сейчас зазвучит музыка, и надо представить себе, куда она нас приглашает. Пациент сидит в удобном кресле, его глаза открыты (у людей, страдающих болезнью Альцгеймера, предложение закрыть глаза может вызвать состояние беспокойства). Не существует готового текста для конкретной музыки, всё происходит спонтанно, желательно лишь придерживаться двух этапов процесса. На первом этапе инструктор включает музыку и через некоторое время задаёт общие вопросы: где мы, в какой стране? Какая эпоха, век? Что мы видим вокруг? Как одеты люди? Что они делают? Какой пейзаж? Какое время года, время суток? Какие краски преобладают? Какая обстановка? Обычно устанавливается довольно пространный диалог между пациентом и инструктором. Образы, вызываемые музыкой, отличаются, как правило, особой яркостью, что характерно для первого, эстетического уровня (в соответствии с классификацией д. Амир). Инструктор плавно переводит диалог на личностные воспоминания собеседника - второй, психодинамический, уровень: бывали ли вы в этом месте? Были ли там ваши друзья, знакомые, семья? Эпизод, сохранившийся в памяти? Если чувствуется, что воспоминания по какой-либо причине неприятны паци- 
енту или он предпочитает не говорить о себе, желательно перевести разговор на темы литературы, театра, изобразительного искусства, связанные с образами, порождёнными данной музыкой, то есть остаться на эстетическом уровне. В процессе общения инструктор должен очень чутко улавливать малейшие изменения в вербальных и невербальных реакциях человека (он устал, ему стало скучно, ему неприятен данный вопрос) и соответственно выстраивать продолжение или завершение занятия.

Особое значение придаётся музыкальной основе «путешествия». При выборе произведения необходимо учитывать информацию о пациенте, чтобы по возможности предугадать личностные ассоциации, избежать проблемных моментов. В связи с этим предпочтительнее формат индивидуальных встреч (не исключено, впрочем, и проведение подобных занятий в небольших группах). Рекомендуется подготовить несколько различных музыкальных фрагментов это позволит подобрать музыку, соответствующую эмоциональному состоянию пожилого человека в данный момент.

Морено для своего метода образных ассоциаций под музыку предлагает использовать малоизвестные музыкальные фрагменты, чтобы не возникали особые ассоциации, мешающие свободному и спонтанному развитию процесса. Для работы с людьми, страдающими болезнью Альцгеймера, в подобном ограничении репертуара нет необходимости - узнаваемость музыки может послужить дополнительным стимулом для общения и воспоминаний. Морено справедливо отмечает, что один и тот же музыкальный фрагмент может вызывать различные чувства и ассоциации у разных людей, так как эмоциональные реакции субъективны. «В то же время в самом широком смысле вне зависимости от субъективных причин (или же благодаря им) определённый тип музыки воспринимается большинством лю- дей как спокойный и, напротив, другой тип большинство людей воспринимают как возбуждающий» [4, с. 103]. Есть музыкальные произведения, вызывающие более или менее обусловленные ассоциации (например, зажигательные латиноамериканские танцы - бразильский карнавал).

«Музыкальные путешествия» с произведениями эпохи барокко, как правило, получаются яркими и позитивными: музыка с лёгкостью вызывает слушателей на контакт, порождая у них оригинальные ассоциации и разнообразные темы для общения. В процессе занятий наблюдаются заметные улучшения в вербальном самовыражении пациента: расширяется его словарный запас, речь становится более плавной и логичной. Несколько иное, особое развёртывание приобрели «музыкальные путешествия" с сюитой Г.Ф. Генделя «Музыка на воде». Символично, что по одной из версий, произведение было написано для исцеления английского короля Георга I от провалов в памяти и глубочайших депрессий. Будучи глубоко религиозным человеком, Георг I часто перечитывал Библию и знал историю о царе Сауле, приступы депрессии которого излечивал юный Давид своей игрой на лире. Этот эпизод и побудил короля обратиться к Генделю с просьбой написать для него чудотворную музыку, способную избавить его от недуга. Неизвестно, как повлияла музыкотерапия на короля Георга I, не исключено, что помогла: по мнению некоторых современных исследователей, прослушивание музыки барокко стимулирует секрецию эндорфинов «гормонов радости» [8, с. 185]. Аналоги эндорфинов применяются в медицине для лечения депрессивных расстройств.

Alla Hornpipe - одна из самых ярких и популярных частей сюиты «Музыка на воде» - как правило, вызывает у пожилых людей положительные эмоции и в чём-то сходные ассоциации. Определяя место, где могла бы звучать подобная 
музыка, пациенты обычно называют зал королевского дворца или открытое пространство перед дворцом. Фантазируя о событии, сходятся на том, что оно напоминает торжество: королевский бал, обед, приём важных гостей, иностранных делегаций. В описаниях интерьера преобладают светлые краски: залитое солнцем пространство, освещённый зал, в нарядах людей доминируют яркие тона. Нередко в рассказе возникают исторические или литературные образы, навеянные музыкой. После первого этапа обычно следует переход к вопросам, пробуждающим личностные воспоминания пациента. Однако встречаются и иные типы развёртывания процесса образного представления под музыку. В практике «музыкальных путешествий» были пациенты, у которых именно звучание Alla Hornpipe буквально с первых же тактов вызывало непосредственный переход на второй этап - воспоминания (без первого, описательного, этапа). После вопроса «где мы?» человек начинал рассказывать значимый эпизод из своей жизни, не связанный напрямую со звучащей музыкой.

В жизни одной из пациенток гериатрического центра для страдающих болезнью Альцгеймера средней степени тяжести примерно тридцать лет назад произошла трагедия - умерла в молодом возрасте от рака единственная дочь. Жизнь для женщины потеряла всякий смысл: она замкнулась в себе, перестала общаться. Периодически лечилась в психиатрических отделениях, позже, в связи с прогрессирующей болезнью Альцгеймера, её поместили в специализированный медицинский центр. Она не создавала никому проблем, ничего не просила, вербальная коммуникация с персоналом ограничивалась словами: «да», «нет», «спасибо». И с племянницей, регулярно приходившей её навещать, женщина тоже не разговаривала: сидела с отрешённым видом и лёгкой улыбкой на лице, не реагируя на искренние попытки родственницы заинтересовать тётю рассказами о событиях в семье.

Я пригласила пациентку в музыкальную комнату, предложила удобное кресло и после краткого разъяснения включила Alla Hornpipe Генделя. С первых же тактов произведения её взгляд стал более концентрированным, мышцы лица напряглись, она выпрямилась в кресле. Я спросила, где, по её мнению, могла звучать такая музыка. Она ответила, что это Рим, большая площадь, в центре - фонтан, украшенный множественными скульптурами. И неожиданно сама начала рассказывать. Ей было сложно говорить, так как эмоции захлёстывали, выпадали из памяти нужные слова, она путалась, возвращаясь к событиям по нескольку раз, но продолжала своё повествование. Женщина вспомнила о том, как впервые узнала о болезни дочери, как приняла решение начать путешествовать с дочерью, чтобы та успела как можно больше увидеть в отпущенный ей срок. Семья арендовала автомобиль с прицепом, в котором была обустроена домашняя обстановка, создающая для дочери определённый комфорт. Они объездили много интересных мест, Рим поразил своим величием, перенося в разные эпохи и отрешая от повседневных проблем. Рим оказался последним в их путешествиях...

После этого занятия жизнь пациентки изменилась: она легче шла на контакт с персоналом, общалась и с пациентами в отделении, искренне интересовалась их состоянием, старалась всем предложить свою помощь. Мы продолжили наши встречи в музыкальной комнате: слушали музыку барокко, говорили о скульптуре и архитектуре. Её речь во время занятий становилась более ровной и связной. Она припоминала интересные эпизоды своих путешествий, вновь и вновь рассказывая о болезни дочери, но уже спокойно, без эмоционального накала.

Интересный случай представляет и другая пациентка гериатрического отде- 
ления для людей, страдающих болезнью Альцгеймера средней степени тяжести. Её состояние отличает высокий уровень тревожности в сочетании с довольно серьёзными нарушениями краткосрочной памяти: каждый вопрос она повторяет большое количество раз, невзирая на то, что получила на него ответ. Состояние беспокойства, как правило, связано с навязчивыми идеями о том, что надо куда-то идти, быстро собирать вещи, чтобы не опоздать. У пациентки серьёзные проблемы с речью: она не может выстроить предложение, затрудняется подобрать нужное слово, часто заменяет его другим, похожим по звучанию. Коммуникация с ней осложнена, персоналу приходится бесконечное количество раз отвечать на один и тот же вопрос, потому что, не получив ответа, женщина впадает в состояние беспокойства, начинает кричать и метаться. У пациентов отделения она вызывает раздражение, невольно провоцируя вспышки гнева с их стороны.

В один из таких «беспокойных" дней женщина была приглашена в музыкальную комнату. Она говорила о том, что ей надо спешить, что она опаздывает, и повторяла это вновь и вновь. В комнате она не согласилась сесть в кресло, настолько была возбуждена. Без каких бы то ни было объяснений зазвучал Alla Hornpipe Генделя. Она замолчала, прислушалась, присела в кресло. «Атлит, крепость...», произнесла она, продолжая прислушиваться к музыке, её взгляд стал осмысленным, направленным вдаль. При ответе на вопросы она сбивалась, путала слова, но в результате получился довольно конструктивный диалог, во многом проясняющий её душевное состояние.

Пациентка родилась в Польше, с детства вместе со старшими братьями посещала собрания прогрессивно настроенной молодёжи, убеждённой в том, что любыми путями надо пробираться в Эрец Исраэль, в Землю Израиля. Родители были против: страх бросить всё и начать жизнь в незнакомом месте переси- ливал уговоры детей. Братья решились на нелегальную иммиграцию, прихватив с собой сестру, которой было 14 лет. В спешке собрав необходимые вещи и немного еды, они проникли на корабль (один из последних, давших возможность спастись от ужасов холокоста). Она не помнила подробностей этого плавания - всё слилось в один кошмар: теснота, сильная качка, брызги солёной воды и постоянное ощущение страха. Следующий эпизод, сохранившийся в её памяти, - красивое спокойное море, солнечные блики на воде и крепость на суше - Атлит. Все вокруг были радостно возбуждены, что наконец-то приплыли, мечта о Земле Израиля осуществилась. Рассказывая это, женщина обретала приподнятое настроение, глаза блестели, улыбка не сходила с лица. В отделение она вернулась напевая и пританцовывая.

Последующие занятия в музыкальной комнате выстраивались вокруг темы «Атлит»: воспоминания о людях из разных стран сочетались с песнями, привезёнными отовсюду и переведёнными на иврит, элементами танцев, рассказами о традициях, фотографиями. Атлит лагерь для перемещённых лиц, созданный британскими властями в период Второй мировой войны, существование в нём, по историческим источникам, было довольно проблематичным. Для девочки-подростка Атлит стал первым домом на родине, к которой она так стремилась, видимо, поэтому её отзывы о нём были окрашены в светлые радостные тона. Регулярные музыкальные занятия оказали положительное влияние на состояние пациентки. Она стала значительно спокойнее, существенно снизился уровень тревожности, улучшилась коммуникация. Встречая меня, она всегда улыбалась и с удовольствием шла в музыкальную комнату.

Анализируя явление непосредственного перехода пациентов под влиянием Alla Hornpipe на уровень личностных 
воспоминаний, достаточно сложно вывести единый алгоритм процесса. Можно предположить, что торжественная величественная музыка Генделя вызвала в памяти пожилых людей вид площади в Риме или крепости Атлит в Израиле. Возможно, на эмоциональном уровне произведение оказалось созвучным ощущениям радости и восторга, сопровождавшим значимые в прошлом события их жизни. Не исключено, что Гендель действительно создал исцеляющую музыку, или стиль музыкального барокко в целом оказывает положительное влияние на память - эти и подобные проблемы ещё предстоит изучать.

Методика «Музыкальные путешествия» направлена на улучшение коммуникации с людьми, страдающими болезнью Альцгеймера, и не ставит перед собой задачи, связанные с решением психологических проблем пациентов. Тем не менее удачно подобранное музыкальное произведение, как «скоростное шоссе к памяти» [3, с. 391], оживляя воспоминания, оказывает на человека терапевтическое воздействие. И в этом — целительный эффект музыки.

\section{a литеРАТУРА $\sim$}

1. Гудимова С.А. Музыкальное пространство барокко // Вестник культурологии. Архив. 2018. № 4 (78). С. 57-69.

2. Декер-Фойгт Г.-Г. Введение в музыкотерапию. СПб.: Питер, 2003. 208 с.

3. Драйден Г., Вое Д. Революция в обучении. М.: Парвинэ, 2003. 671 с.

4. Морено Дж. Дж. Включи свою внутреннюю музыку. Музыкальная терапия и психодрама. М.: Когито-Центр, 2009. 143 с.

5. Піхтар О.А. Активізація мислення у студентів засобами музикотерапіі // Наукові праці. Вип.95. Том 108. С. 57-61.

6. Рева В.П. Генезис научной мысли о восприятии музыки в исторической ретроспективе // Збірник наукових праць. 2014. № 2 (17). С. 303-314.

7. Сливка Л.В. Музикотерапія в освітньому процесі: історичне і теоретичне підгрунтя // Науковий вісник Ужгородського національного університету. Серія «Педагогіка. Соціальна робота». Випуск 37. 2015. С. 164-166.

8. Соколова А.В. Вплив музики на мозок людини // Науковий вісник Південноукраінського національного педагогічного університету імені К.Д. Ушинського. Педагогічні науки. Одеса, ПНПУ ім. К.Д. Ушинського, 2013. № 7-8. С. 183-188.

9. Шутова Н.В. Структурно-динамический подход к использованию музыки в воздействии на личность // Вестник Санкт-Петербургского университета. 2009. Сер. 12. Социология, психология, педагогика. Вып. 3. Ч. ІІ. С. 282-288.

10. . . אמיר ,ד' (1999). להיפגש עם הצלילים, תרפיה במוסיקה: פרקטיקה, תיאוריה ומחקר, רמת גן: הוצאת אוניברסיטת בר-אילן.

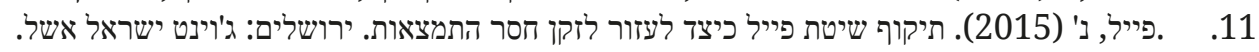

Об авторе:

Гершбейн Татьяна шмуэлевна, музыковед, психолог, докторант кафедры компаративной литературы, университет им. Бар-Илана (5290002, г. Рамат-Ган, Израиль); музыкальный терапевт, Медицинский гериатрический центр (6195001, г. Тель-Авив, Израиль).

ORCID: 0000-0003-4282-1491, tatiana854@gmail.com 


\section{e REFERENCES $\sim$}

1. Gudimova S.A. Muzykal'noe prostranstvo barokko [The Musical Space of the Baroque]. Vestnik kul'turologii. Arkhiv [Bulletin of Cultural Studies. Archive]. 2018. No. 4 (78), pp. 57-69.

2. Deker-Foygt G.-G. Vvedenie v muzykoterapiyu [Introduction to Music Therapy]. St. Petersburg: Piter, 2003. 208 p.

3. Drayden G., Voe D. Revolyutsiya v obuchenii [The Learning Revolution]. Moscow: Parvine, 2003. $671 \mathrm{p}$.

4. Moreno Dzh. Dzh. Vklyuchi svoyu vnutrennyuyu muzyku [Acting Your Inner Music]. Muzykal'naya terapiya i psikhodrama [Music Therapy and Psychodrama]. Moscow: Kogito-Tsentr, 2009. $143 \mathrm{p}$.

5. Pikhtar O.A. Aktivizatsiya mislennya u studentiv zasobami muzikoterapii [The Activation of Thinking among Students with the Help of Music Therapy]. Naukovi pratsi. Issui 95. Volume 108, pp. 57-61.

6. Reva V.P. Genezis nauchnoy mysli o vospriyatii muzyki v istoricheskoy retrospektive [The Genesis of Scientific Thought about the Perception of Music in a Historical Retrospective]. Zbirnik naukovikh prats' [Collection of Scholarly Works]. 2014. No. 2 (17), pp. 303-314.

7. Slivka L.V. Muzikoterapiya v osvitn'omu protsesi: istorichne i teoretichne pidgruntya [Slyvka Larysa. Music Therapy in the Educational Process: Historical and Theoretical Basis]. Naukoviy visnik Uzhgorods'kogo natsional'nogo universitetu. Seriya "Pedagogika, sotsial'na robota". Vipusk 37 [Scientific Herald of Uzhgorod National University. Series "Pedagogy. Social Work”. Issue 37]. 2015, pp. 164-166.

8. Sokolova A.V. Vpliv muziki na mozok lyudini [The Influence of Music on the Human Brain]. Naukoviy visnik Pivdennoukrains'kogo natsional'nogo pedagogichnogo universitetu imeni K.D. Ushins'kogo. Pedagogichni nauki [Scientific Bulletin of South Ukrainian National Pedagogical University named after K.D. Ushynsky. Pedagogical sciences]. Odessa, South Ukrainian National Pedagogical University named after K.D. Ushynsky, 2013. No. 7-8, pp. 183-188.

9. Shutova N.V. Strukturno-dinamicheskiy podkhod k ispol'zovaniyu muzyki v vozdeystvii na lichnost' [Structural-Dynamic Approach to the Musical in Influence on Personality]. Vestnik Sankt-Peterburgskogo universiteta [Vestnik of Saint Petersburg University]. 2009. Series 12. Psychology. Sociology. Education. Issue 3. Part II, pp. 282-288.

10. Amir D. Lehipagesh im hatslilim. Terapia bemusika: praktika, teoria vemehkar [Amir D. Meeting the Sounds. Music Therapy: Practice, Theory and Research]. Ramat-Gan: hotseat universitat Bar-Ilan [Ramat-Gan: Bar-Ilan University]. 1999. 219 p.

11. Feil N. Tikuf shitat Feil. Keitsad laazor lazaken hasar hitmats'ut. [Feil N. Validation. The Feil Method. How to Help Disoriented Old]. Erushalaim: Joint Israel Eshel [Jerusalem: The Joint Israel Eshel]. 2015. 147 p.

\section{About the author:}

Tatiana Sh. Gershbeyn, musicologist, psychologist, doctoral student at the Department of Comparative Literature, Bar-Ilan University (5290002, Ramat Gan, Israel);

music therapist, Medical Geriatric Center

(6195001, Tel-Aviv, Israel).

ORCID: 0000-0003-4282-1491, tatiana854@gmail.com

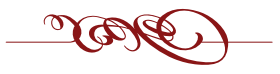

